\title{
AQUEOUS EXTRACT OF FALLEN INDIAN SOAPBERRY (SAPINDUS MUKOROSSI) LEAVES DECREASED SEED GERMINATION BUT INCREASED SEEDLING GROWTH OF FOUR VEGETABLES
}

\author{
LI, Y. ${ }^{1,2}-\mathrm{LI}, \mathrm{X} .{ }^{3}-\mathrm{LI}, \mathrm{Q} .{ }^{1}-$ YUE, M..$^{{ }^{*}}$ \\ ${ }^{I} X i$ 'an Botanical Garden of Shaanxi Province, Institute of Botany of Shaanxi Province, Xi'an \\ 710061, China \\ ${ }^{2}$ Shaanxi Engineering Research Centre for Conservation and Utilization of Botanical \\ Resources, Xi'an 710061, China \\ ${ }^{3}$ Shaanxi Institute of Technology, Xi'an 710300, China \\ ${ }^{*}$ Corresponding author \\ e-mail: yueming@nwu.edu.cn; phone: +86-29-8525-1800; fax: +86-29-8525-1800
}

(Received $15^{\text {th }}$ Aug 2020; accepted $28^{\text {th }}$ Oct 2020)

\begin{abstract}
Utilization of fallen leaves is one challenge for modern sustainable agriculture. Allelopathy is selective, depending upon the concentrations of extracts and receptor species. Therefore, we conducted an experiment to confirm how the aqueous extract of fallen leaves of Sapindus mukorossi, an important virescent tree species in south China, affected seed germination and seedling growth of four common vegetables, Brassica rapa var. chinensis, B. oleracea var. capitata, Lactuca sativa L., and Chrysanthemum coronarium L. Our results showed that the fallen leaf aqueous extracts inhibited the seed germination of the four vegetables. Moreover, the aqueous extracts stimulated seedlings growth of the four vegetables especially at appropriate concentration treatments. The effects of fallen leaf aqueous extracts on seedlings were related to phylogenic characteristics and morphological characteristics of cultivated vegetables. According to our study, by and large, fallen leaf aqueous extracts of S. mukorossi decreased seed germination and increased seedling growth. Thus, we may take advantage of the negative allelopathic effects on germination via applying aqueous extracts after crop emergence to control weeds, and the positive allelopathic effects on seedling growth to stimulate crop yield in agriculture. Our results represent a step forward in the study of weed management and organic fertilizer by allelochemicals.
\end{abstract}

Keywords: soapnuts, allelochemicals, biomass accumulation, morphological characteristics, life form

\section{Introduction}

Allelopathy is defined as the influence of chemical substances produced by plants and released into the surrounding environment affecting the growth, development, survival, and reproduction of neighboring plants (Rice, 1984). Allelochemicals are plant secondary metabolites such as saponins, tannins, flavonoids, terpenoids, and lactones (Caser et al., 2020), which are totally or partially water-soluble substances (Turk and Tawaha, 2003) that are released into environment through leaching, exudation, vaporization or decomposition (Fernandez et al., 2009). All plant organs could produce or store allelochemicals. Allelopathy has been found to widely exist in nature, and play important roles in ecosystem (Chou, 1999; Rout and Callaway, 2009; Zheng et al., 2014). Allelopathy has been suggested as an important mechanism contributing to the impressive success of invasive plants (Hierro and Callaway, 2003; Ooka and Owens, 2018), and can be one of the significant factors contributing to species distribution (Mallik, 2003). Furthermore, allelopathy has been theorized to play important roles in maintaining community stabilities by inhibiting 
the invasion of newly introduced species (Callaway and Aschehoug, 2000; Mallik and Pellissier, 2000; Morgan and Overholt, 2005; Veen et al., 2019).

More and more studies have proved that allelochemicals released from plants not only play harmful effects on other plants, but also can benefit neighboring plants growth. The allelopathic effects are selective, depending upon the concentrations of extracts and receptor species (Turk and Tawaha, 2003; Cheema et al., 2013). For example, leaf aqueous extracts of Castanea henryi reduced seed germination, seedling growth of Zea mays and Brassica pekinensis at high concentrations in a recent study. However, extracts of low concentrations in this study promoted seed germination, shoot growth of Z. mays, but not for B. pekinensis (Ming et al., 2020). Nowadays, the potential selective impacts of allelopathy have been utilized in modern sustainable agriculture. In order to effective control of weeds, reduction of the input of chemical pesticides is feasible by utilizing negative allelopathic effects of crops on weeds (Anwar et al., 2018; Campos et al., 2019; Kong et al., 2019; Ojija et al., 2019). Furthermore, it is possible to promote crop yields by utilizing positive allelopathic effects (Iqbal et al., 2011). Reductions of the input of chemical pesticides and fertilizer permit the development of crops with low phytotoxic residue amounts in water and soil, thus facilitating environment safe (Cheng and Cheng, 2015).

The genus Sapindus mukorossi, better known as the soapnuts, has an extensive distribution spanning in tropical and sub-tropical of Asia (Singh et al., 2015). S. mukorossi is a traditional and important virescent tree species in the area south of Yangtze River of China (Diao et al., 2016; Ling et al., 2019). As a deciduous tree, S. mukorossi produce a large amount of fallen leaves every year, and such litter represents both a huge waste of resources and a potential pollutant. Therefore, it would be urgently to develop practical uses for the fallen leaves.

Although according to previous studies that leaf extracts of S. mukorossi contain different types of flavonoids such as quercetin, apigenin, kaempferol, and rutin (Singh et al., 2015), the allelopathic effects of leaf aqueous extracts is not clear. Thus, the aim of the present study was to investigate the allelopathic effects of fallen leaf aqueous extracts of $S$. mukorossi on the seed germination and seedling growth of four common vegetables in China, Brassica rapa var. chinensis, Lactuca sativa L., Chrysanthemum coronarium L., and Brassica oleracea var. capitata. Furthermore, in order to observe whether allelopathic effects of fallen leaf aqueous extracts of $S$. mukorossi on vegetables are depending on phylogeny, we took phylogenic characteristics into account when we selected the four tested vegetables: $B$. rapa and B. oleracea are two Crucifer species, while $L$. sativa and $C$. coronarium are two Asteraceae species. Understanding allelopathic effects on other plants especially crops is meaningful for rational, sustainable, and economical utilization of resources of fallen leaves.

\section{Materials and Methods}

\section{Preparation of leaf aqueous extracts}

Fallen leaves of Sapindus mukorossi were collected in Xi'an Botanical Garden of Shaanxi Province ( $34^{\circ} 21^{\prime}$ N, $108^{\circ}$ 96' E, alt. $413 \mathrm{~m}$ asl), China, in December 2019. Fallen leaves were air dried in shade for a week after collection. The dried leaves were ground using mortar then passed through $2 \mathrm{~mm}$ mesh sieve. $40 \mathrm{~g}, 20 \mathrm{~g}, 10 \mathrm{~g}, 5 \mathrm{~g}, 0 \mathrm{~g}$ (control) of the ground materials were soaked in $1000 \mathrm{ml}$ sterilized distilled water. These gave the concentration of leaf aqueous extracts were $40 \mathrm{~g} / \mathrm{L}, 20 \mathrm{~g} / \mathrm{L}, 10 \mathrm{~g} / \mathrm{L}, 5 \mathrm{~g} / \mathrm{L}$, and $0 \mathrm{~g} / \mathrm{L}$ 


$$
-333-
$$

(control). The mixtures were then shaken intermittently and allowed to stand for 24 hours in the laboratory at $25{ }^{\circ} \mathrm{C}$. Thereafter, the suspensions were filtered by filter paper. All extracts were refrigerated at $4{ }^{\circ} \mathrm{C}$.

\section{Seed collection and germination}

Seeds of B. rapa, L. sativa, C. coronarium, and B. oleracea were selected in our study. The four vegetables seeds were obtained from suburban vegetable farm in Xi' an, China. The seeds were surface sterilized with 5\% sodium hypochlorite. After 15 minutes, seeds were rinsed severally with distilled water to remove the excess of the chemical. Thereafter, seeds were primed in distilled water for 1 hour. 30 seeds of each vegetable were placed on filter paper in petri dishes (diameter: $9 \mathrm{~cm}$, height: $2 \mathrm{~cm}$ ). Each petri dish with clearly labeled was moistened with $2 \mathrm{ml}$ leachate of one of five concentrations. Then seeds from each vegetable were subjected to 5 treatments $(0 \mathrm{~g} / \mathrm{L}, 5 \mathrm{~g} / \mathrm{L}, 10 \mathrm{~g} / \mathrm{L}, 20 \mathrm{~g} / \mathrm{L}$, and $40 \mathrm{~g} / \mathrm{L}$ ). There were 3 replications. All the petri dishes were placed in incubator at a constant temperature of $25^{\circ} \mathrm{C}$ with 12 hours light. Numbers of germinated seed were recorded every 24 hours. Germination experiment was terminated after 15 days, and seedlings traits were measured. 5 seedlings were randomly harvested from each petri dish to determine seedlings traits (whole seedling length, shoot height, root length, fresh biomass). Root length indicated the length of the longest root. All seedlings were measured for seedling traits if there were less than 5 seedlings.

\section{Index of germination and seedling growth}

Germination percentage (GP) was calculated by

$$
G P(\%)=\frac{\sum n_{i}}{T} \cdot 100
$$

Germination index $(G I)$ is a time-weighted cumulative germination that measures the speed of germination and quantifies the seedling vigor. GI was calculated by

$$
G I=\frac{\sum n_{i}}{t}
$$

Mean germination time (MGT) was used as an index to evaluate the phenomenon of germination speed. It is a measurement of the average length of time required for maximum germination of a seed lot (Ranal and Santana, 2006). MGT was calculated by

$$
M G T=\frac{\sum_{i=1}^{k} n_{1} t_{i}}{\sum_{i=1}^{k} n_{1}}
$$

The synchronization index (SI) can describe emergence patterns, with a higher index representing a more uniform germination (Ranal and Santana, 2006). SI was calculated by

$$
\begin{gathered}
S I=\frac{\sum C_{n_{i}, 2}}{N} \\
C_{n_{i}, 2}=n_{i}\left(n_{1}-1\right) / 2 \\
N=\sum n_{i}\left(\sum n_{i}-1\right) / 2
\end{gathered}
$$




$$
-334-
$$

Vigor index (VI), a comprehensive account for acorn germination and seedling growth, is a suitable index to evaluate seed vigor (Ranal and Santana, 2006). VI was calculated by

$$
V I=G I \cdot S
$$

In these formulae above, $n_{i}$ refers to the number of seeds germinated in time $i$ (not the accumulated number, but the number corresponding to the $i^{\text {th }} C_{n_{i}, 2}$ observation); $T$ is the total number of tested seeds; $S$ represents the average whole length on the $15^{\text {th }}$ day; $t_{\mathrm{i}}$ refers to the time from the strat of the experiment to the $i^{\text {th }}$ observation (days); and $k$ is the last germination time.

\section{Data analysis}

Two-way ANOVAs were used to examine the effects of phylogenic characteristic $(\mathrm{P})$, concentration of fallen leaf aqueous extracts of $S$. mukorossi $(\mathrm{C})$, and their interaction on seed germination traits (germination percentage, germination index, mean germination time, the synchronization index) and seedling traits (seedling whole length, shoot length, root length, vigor index, fresh biomass). One-way ANOVAs were used to examine the effects of leaf aqueous extracts of different concentrations on seed germination traits and seedling traits for one species. Tukey's test was used to compare the significance among treatments for one species. All the above statistical analyses were conducted with SAS software (SAS Institute Inc., Cary, NC, USA).

Structural equation models (SEMs) were used to investigate the direct and indirect effects of leaf aqueous extracts on seed biomass accumulation for the four test vegetables. Amos 17.0.2 (Amos Development Corporation, Chicago, IL, USA) was used to parameterize the SEM model.

\section{Results}

\section{Germination}

As a whole, phylogenic characteristic (P) did not affected germination percentage (GP) $(P>0.05$, Table 1$)$. While GP significantly decreased with the concentration of fallen leaf aqueous extracts of $S$. mukorossi (C) increased as a whole $(P<0.05$, Table 1$) .20 \mathrm{~g} / \mathrm{L}$ and $40 \mathrm{~g} / \mathrm{L}$ extracts significantly reduced the whole GP by $50.28 \%$ and $65.28 \%$, respectivily. According to One-way ANOVAs, fallen leaf aqueous extracts of $S$. mukorossi significantly affected GPs of the four vegetables (all $P<0.05$, Table 2). GPs of the four vegetables were all decreased as the concentration increased (Fig. 1). Compared with distilled water control treatment, $20 \mathrm{~g} / \mathrm{L}$ and $40 \mathrm{~g} / \mathrm{L}$ extracts significantly reduced GP of B. rapa by $58.89 \%$ and $84.44 \%$, and reduced GP of B. oleracea by $90.00 \%$ and $100.00 \%$, whereas $5 \mathrm{~g} / \mathrm{L}$ and $10 \mathrm{~g} / \mathrm{L}$ extracts had no significant effects (Fig. 1). For C. coronarium, aqueous extracts reduced GP by $27.78 \%, 32.22 \%, 44.45 \%, 61.11 \%$ with concentration increased, respectively (Fig. 1). For L. sativa, $40 \mathrm{~g} / \mathrm{L}$ extract significantly reduced GP by $15.56 \%$, whereas the other extracts had not significant effects compared with distilled water control treatment. 


$$
-335 \text { - }
$$

Table 1. Effects of phylogenic characteristic $(P)$, concentration of fallen leaf aqueous extracts of $S$. mukorossi $(C)$, and their interaction on seed germination traits and seedling traits based on two-way ANOVAs

\begin{tabular}{c|c|cc|cc|cc}
\hline \multicolumn{2}{c|}{} & \multicolumn{2}{c|}{$\begin{array}{c}\text { Phylogenic } \\
\text { characteristic }(\mathbf{P})\end{array}$} & \multicolumn{2}{|c|}{ Concentration $(\mathbf{C})$} & \multicolumn{2}{c}{ P*C } \\
\cline { 3 - 8 } \multicolumn{2}{c|}{} & F-Value & $\boldsymbol{P}$-Value & F-Value & P-Value & F-Value & P-Value \\
\hline \multirow{6}{*}{ Seed } & GR & 1.34 & 0.25 & 22.70 & $<.001$ & 6.26 & $<.001$ \\
& GI & 17.55 & $<.001$ & 56.09 & $<.001$ & 12.78 & $<.001$ \\
& MGT & 0.95 & 0.33 & 2.44 & 0.06 & 0.30 & 0.87 \\
& SI & 5.38 & $<.05$ & 9.32 & $<.001$ & 0.51 & 0.73 \\
\hline \multirow{6}{*}{ Seedling } & Shoot length & 4.73 & $<.05$ & 9.13 & $<.001$ & 2.70 & $<.05$ \\
& Root length & 13.83 & $<.001$ & 3.25 & $<.05$ & 1.28 & 0.29 \\
& Whole length & 10.02 & $<.05$ & 8.28 & $<.001$ & 1.63 & 0.18 \\
& S/R & 16.13 & $<.001$ & 0.82 & 0.52 & 2.13 & 0.09 \\
& VI & 13.45 & $<.001$ & 10.91 & $<.001$ & 4.39 & $<.05$ \\
& Biomass & 24.97 & $<.001$ & 1.90 & 0.13 & 1.71 & 0.16 \\
\hline
\end{tabular}

GP: germination percentage; GI: germination index; MGT: mean germination time; SI: the synchronization index; S/R: the rate of shoot length to root length; VI: vigor index

Table 2. Results of one way ANOVAs on the effects of fallen leaf aqueous extracts of $S$. mukorossi on seed germination and seedling growth characters of the four vegetables. See Table 1 for abbreviations

\begin{tabular}{|c|c|c|c|c|c|c|c|c|c|}
\hline & & \multicolumn{2}{|c|}{ B. rapa } & \multicolumn{2}{|c|}{ L. sativa } & \multicolumn{2}{|c|}{ C. coronarium } & \multicolumn{2}{|c|}{ B. oleracea } \\
\hline & & F-Value & $P$-Value & F-Value & $P$-Value & F-Value & $P$-Value & F-Value & $P$-Value \\
\hline \multirow{4}{*}{ seed } & GP & 17.20 & $<.001$ & 3.88 & $<.05$ & 26.12 & $<.001$ & 67.70 & $<.001$ \\
\hline & GI & 38.87 & $<.001$ & 9.57 & $<.05$ & 14.50 & $<.001$ & 58.77 & $<.001$ \\
\hline & MGT & 202.31 & $<.001$ & 13.70 & $<.001$ & 0.88 & 0.51 & 36.43 & $<.001$ \\
\hline & SI & 4.10 & $<.05$ & 7.70 & $<.05$ & 25.54 & $<.001$ & 14.89 & $<.001$ \\
\hline \multirow{6}{*}{ seedling } & Shoot length & 19.52 & $<.001$ & 5.03 & $<.05$ & 29.96 & $<.001$ & 4.24 & $<.05$ \\
\hline & Root length & 1.96 & 0.18 & 2.44 & 0.11 & 2.71 & 0.09 & 7.02 & $<.05$ \\
\hline & Whole length & 12.52 & $<.001$ & 8.18 & $<.05$ & 7.76 & $<.05$ & 4.89 & $<.05$ \\
\hline & $\mathbf{S} / \mathbf{R}$ & 0.16 & 0.95 & 0.72 & 0.60 & 13.50 & $<.001$ & 26.61 & $<.001$ \\
\hline & VI & 14.38 & $<.001$ & 4.36 & $<.05$ & 5.39 & $<.05$ & 2.96 & 0.07 \\
\hline & Biomass & 4.57 & $<.05$ & 3.11 & 0.06 & 1.07 & 0.42 & 4.95 & $<.05$ \\
\hline
\end{tabular}

As a whole, phylogenic characteristic $(\mathrm{P})$, concentration of fallen leaf aqueous extracts of $S$. mukorossi (C), and their interaction significantly influenced seed germination index (GI) (all $P<0.001$, Table 1). With the concentration increased, the whole GI decreased by $21.00 \%, 26.86 \%, 70.17 \%$, and $86.90 \%$. In addition, GI of Crucifer species was $36.23 \%$ higher than that of Asteraceae species. According to One-way ANOVAs, GIs of the four vegetables significant decreased with the concentration increased (all $P<0.05$, Table 2). Compared with distilled water treatment, $20 \mathrm{~g} / \mathrm{L}$ and $40 \mathrm{~g} / \mathrm{L}$ extracts significantly reduced GI of B. rapa aqueous by $71.99 \%$ and $95.48 \%$, and reduced GI of L. sativa by $32.41 \%$ and $49.07 \%$, whereas $5 \mathrm{~g} / \mathrm{L}$ and $10 \mathrm{~g} / \mathrm{L}$ extracts had no significant effects (Fig. 2). Aqueous extracts of different concentrations reduced GI of $C$. coronarium by $38.17 \%$, $45.70 \%, 66.13 \%$, and $91.40 \%$, and reduced GI of B. oleracea by $22.22 \%, 35.96 \%$, $94.44 \%$, and $100.00 \%$ (Fig. 2). 

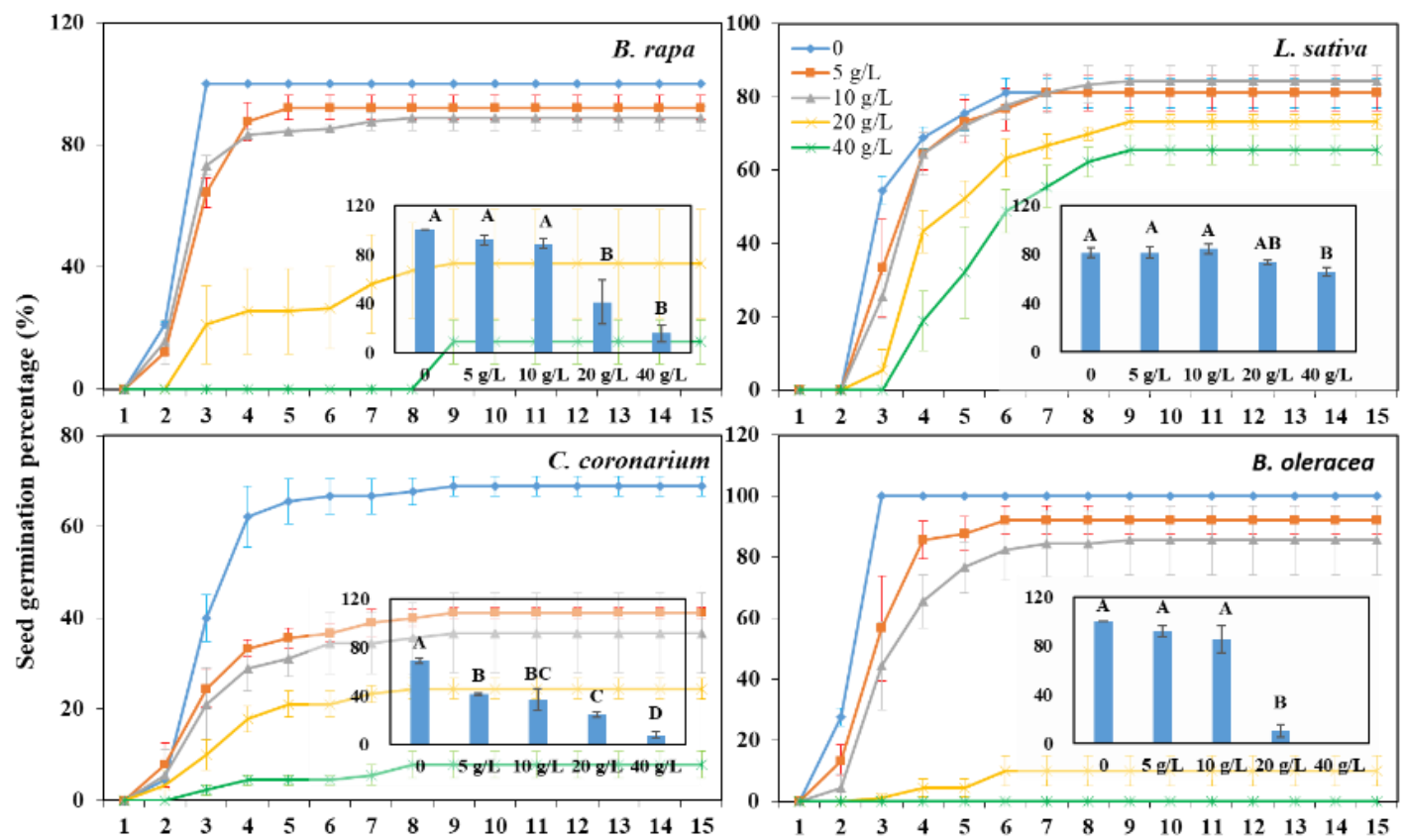

Incubation day

Figure 1. Effects of fallen leaf aqueous extracts of S. mukorossion on seed cumulative germination percentage (\%) and final germination percentage (\%, inserts, means $\pm 1 S E, n=3)$ of the four vegetables. Means with the same uppercase letter are not significantly different $(P>0.05)$
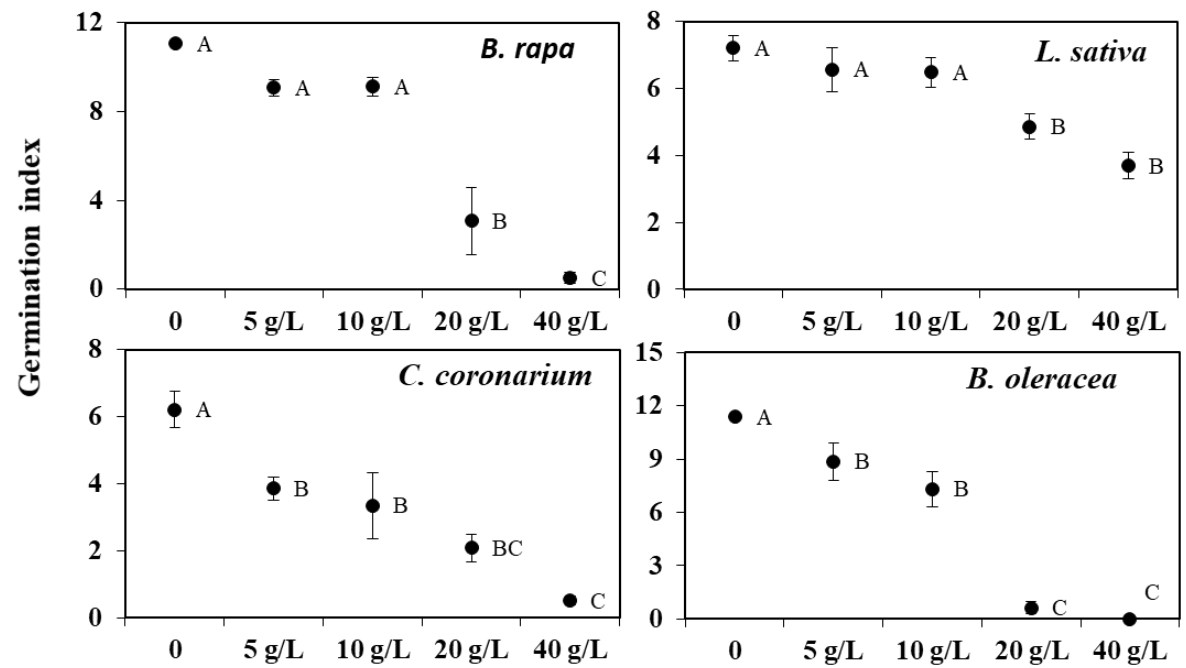

Concentrations

Figure 2. Effects of fallen leaf aqueous extracts of S. mukorossi on seed germination index (GI) of the four vegetables (means $\pm 1 S E, n=3$ ). Means with the same uppercase letter are not significantly different $(P>0.05)$

As a whole, phylogenic characteristic $(\mathrm{P})$, concentration of fallen leaf aqueous extracts of $S$. mukorossi $(\mathrm{C})$, and their interaction all had no effects on mean germination time (MGT) (all $P>0.05$, Table 1). According to One-way ANOVAs, except for 


$$
-337 \text { - }
$$

C. coronarium, MGTs of the other three vegetables significantly increased by aqueous extracts (all $P<0.001$, Table 2). Aqueous extracts of different concentrations prolonged MGT of B. rapa by $15.38 \%, 12.64 \%, 80.40 \%$, and $222.71 \%$, prolonged MGT of $L$. sativa by $11.64 \%, 18.78 \%, 38.12 \%$, and $60.28 \%$, prolonged MGT of B. oleracea by $24.24 \%$, $39.29 \%, 81.52 \%$, and $100.00 \%$ (Fig. 3).

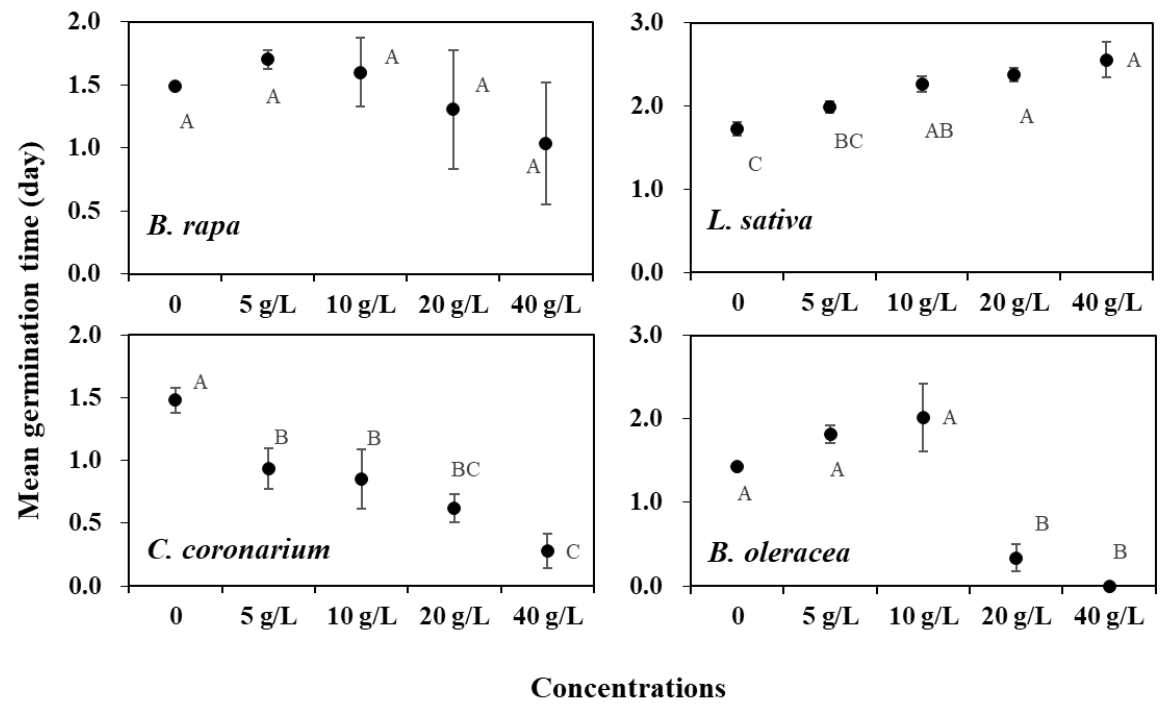

Figure 3. Effects of fallen leaf aqueous extracts of $S$. mukorossion on seed mean germination time $(M G T)$ of the four vegetables (means $\pm 1 S E, n=3$ ). Means with the same uppercase letter are not significantly different $(P>0.05)$

As a whole, phylogenic characteristic $(\mathrm{P})$, and concentration of fallen leaf aqueous extracts of $S$. mukorossi (C) significantly influenced synchronization index (SI) (both $P<0.05$, Table 1). With the concentration increased, the whole SI decreased by $25.22 \%$, $25.23 \%, 52.05 \%$, and $56.62 \%$. In addition, SI of Crucifer species was $25.96 \%$ higher than that of Asteraceae species. According to One-way ANOVAs, fallen leaf aqueous extracts played significantly roles on SIs of the four vegetables (all $P<0.05$, Table 2). Aqueous extracts decreased SI of B. rapa by $30.81 \%, 19.66 \%, 54.93 \%$, and $9.89 \%$, decreased SI of L. sativa by $9.74 \%, 27.74 \%, 29.70 \%$, and $36.76 \%$, decreased SI of $C$. coronarium by $34.95 \%, 27.76 \%, 61.01 \%$ and $88.52 \%$ at $5 \mathrm{~g} / \mathrm{L}, 10 \mathrm{~g} / \mathrm{L}, 20 \mathrm{~g} / \mathrm{L}$, and $40 \mathrm{~g} / \mathrm{L}$ concentrations, respectively (Fig. 4). Aqueous extracts decreased SI of B. oleracea by $61.48 \%$ at $20 \mathrm{~g} / \mathrm{L}$ concentrations (Fig. 4).

\section{Seedling growth}

As a whole, phylogenic characteristic $(\mathrm{P})$, and concentration of fallen leaf aqueous extracts of $S$. mukorossi (C) significantly influenced shoot length, root length, and whole length (all $P<0.05$, Table 1). Phylogenic characteristic $(\mathrm{P})$ played significantly role on $\mathrm{S} / \mathrm{R}$ as a whole $(P<0.05$, Table 1$)$. With the concentration increased, the shoot length increased by $160.00 \%, 248.89 \%, 206.67 \%$, and $136.67 \%$; the whole root length increased by $182.54 \%, 192.53 \%, 147.52 \%$, and $92.53 \%$; the whole length increased by $166.93 \%$, $231.55 \%, 188.47 \%$, and $123.09 \%$. In addition, the shoot length, root length, and whole length of Crucifer species was $27.68 \%, 97.34 \%$, and $84.75 \%$ higher than those of Asteraceae species, respectively. 


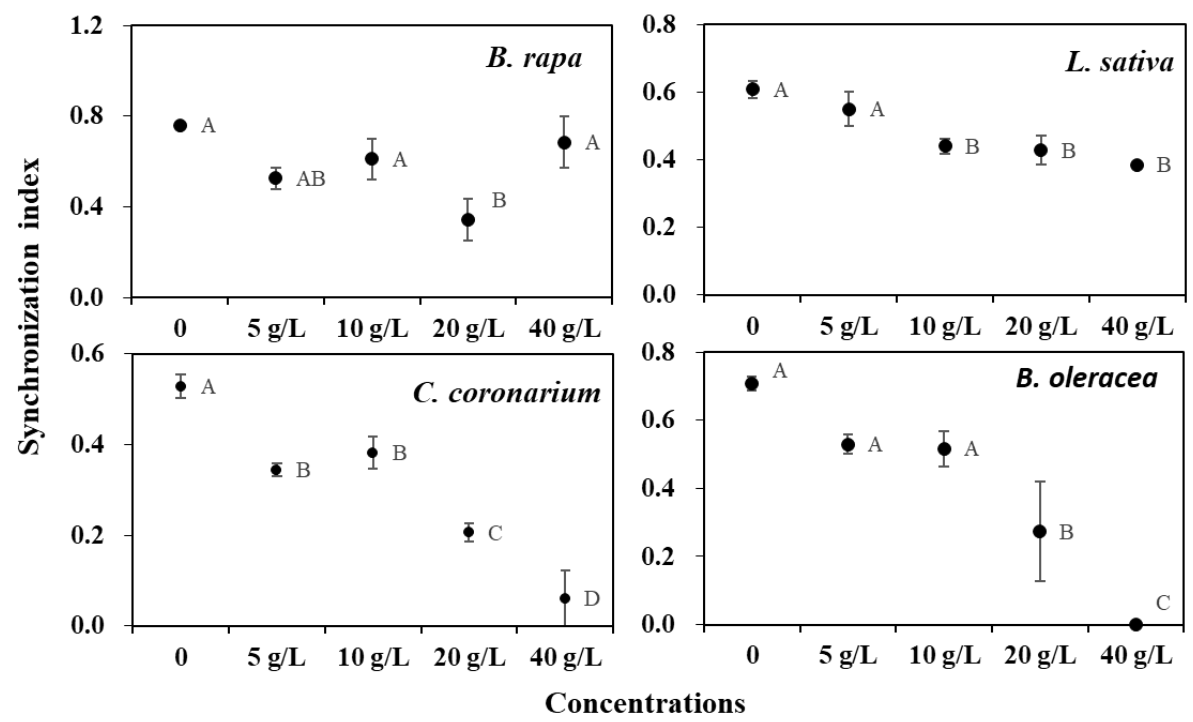

Figure 4. Effects of fallen leaf aqueous extracts of S. mukorossion on seed synchronization index (SI) of the four vegetables (means $\pm 1 S E, n=3$ ). Means with the same uppercase letter are not significantly different $(P>0.05)$

According to One-way ANOVAs, fallen leaf aqueous extracts of $S$. mukorossi significantly increased whole length of the four vegetable seedlings (all $P<0.05$, Table 2 , Fig. 5). Furthermore, aqueous extracts significantly stimulated shoot length of the four vegetables (all $P<0.05$, Table 2 , Fig. 5), whereas the extracts only significantly affected root length of $B$. oleracea $(P<0.05$, Table 2, Fig. 5). However, aqueous extracts only significantly affected S/R of $C$. coronarium and B. oleracea (both $P<0.001$, Table 2). Aqueous extracts significantly stimulated $\mathrm{S} / \mathrm{R}$ of $C$. coronarium by $314.36 \%$ and $328.63 \%$ at $10 \mathrm{~g} / \mathrm{L}$ and $40 \mathrm{~g} / \mathrm{L}$ treatments. Aqueous extracts significantly increased $\mathrm{S} / \mathrm{R}$ of B. oleraceaby $112.90 \%$ at $20 \mathrm{~g} / \mathrm{L}$ treatments and decreased it by $48.84 \%$ at $5 \mathrm{~g} / \mathrm{L}$ treatments (Fig. 5). The $20 \mathrm{~g} / \mathrm{L}$ extract stimulated shoot length and root length by $189.29 \%$ and $146.00 \%$, resulting in $176.93 \%$ stimulation to whole length of $B$. rapa (Fig. 5). The $10 \mathrm{~g} / \mathrm{L}$ extract stimulated shoot length and root length by $533.25 \%$ and $867.00 \%$, resulting in $600.00 \%$ stimulation to whole length of L. sativa (Fig. 5). The $10 \mathrm{~g} / \mathrm{L}$ extract stimulated shoot length and root length by $640.84 \%$ and $59.88 \%$, resulting in $446.60 \%$ stimulation to whole length of C. coronarium (Fig. 5). The $10 \mathrm{~g} / \mathrm{L}$ extract stimulated shoot length and root length by $103.88 \%$ and $146.91 \%$, resulting in $118.75 \%$ stimulation to whole length of B. oleracea (Fig. 5).

As a whole, phylogenic characteristic $(\mathrm{P})$, concentration of fallen leaf aqueous extracts of $S$. mukorossi (C), and their interaction significantly influenced vigor index (VI) (all $P<0.05$, Table 1). $5 \mathrm{~g} / \mathrm{L}$ and $10 \mathrm{~g} / \mathrm{L}$ aqueous extracts significantly stimulated the whole VI by $98.38 \%$ and $135.62 \%$, respectively. In addition, VI of Crucifer species was $90.96 \%$ higher than that of Asteraceae species. According to One-way ANOVAs, fallen leaf aqueous extracts significantly affected VIs of $B$. rapa, $L$. sativa, and $C$. coronarium (all $P<0.05$, Table 2). $5 \mathrm{~g} / \mathrm{L}$ and $10 \mathrm{~g} / \mathrm{L}$ aqueous extracts significantly stimulated VI of $B$. rapa by $101.90 \%$ and $125.00 \%$, stimulated VI of L. sativa by $267.90 \%$ and $479.84 \%$, and stimulated VI of C. coronarium by $139.81 \%$ and $308.32 \%$, respectively (Fig. 6). 


$$
-339 \text { - }
$$
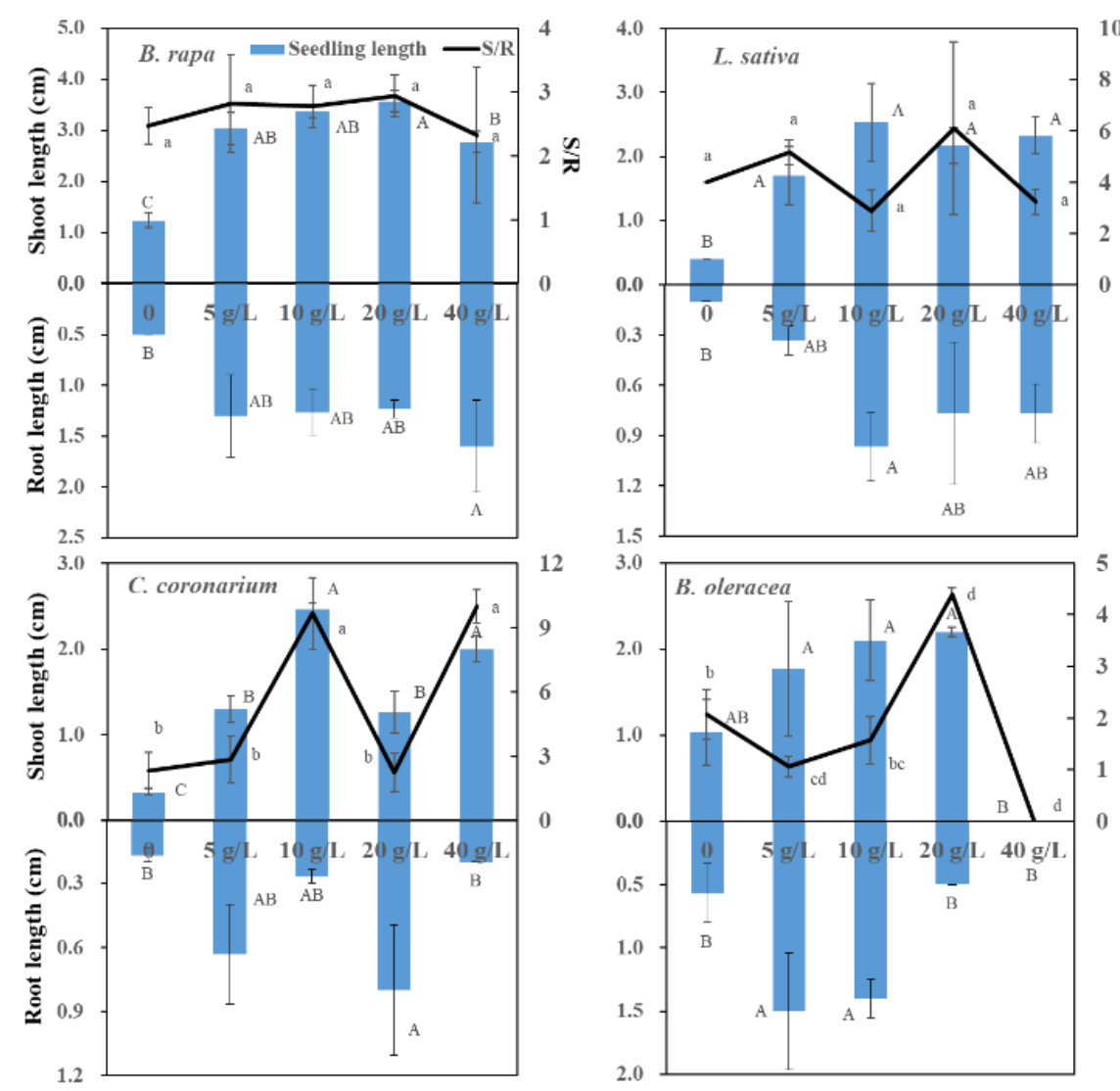

Concentrations

Figure 5. Effects of fallen leaf aqueous extracts of S. mukorossion on seedling length (Column) and $S / R$ (Broken lines) of the four vegetables (means $\pm 1 S E, n=3$ ). Means with the same uppercase letter are not significantly different in shoot length or root lenght $(P>0.05)$. Means with the same lowercase letter are not significantly different in $S / R(P>0.05)$

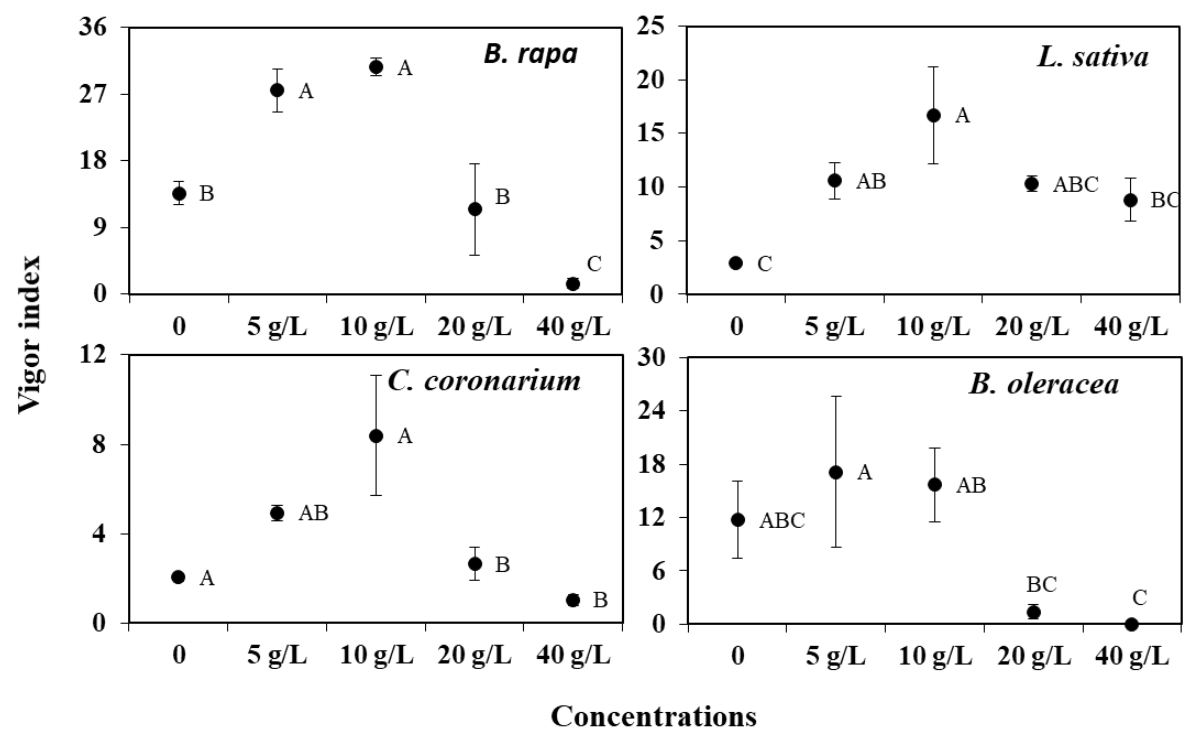

Figure 6. Effects of fallen leaf aqueous extracts of S. mukorossion on seedling vigor index (VI) of the four vegetables (means $\pm 1 S E, n=3$ ). Means with the same uppercase letter are not significantly different $(P>0.05)$ 


$$
-340 \text { - }
$$

Phylogenic characteristic $(\mathrm{P})$ played significantly roles on biomass per plant $(P<0.05$, Table 1). $10 \mathrm{~g} / \mathrm{L}$ aqueous extracts significantly stimulated the whole biomass by $53.30 \%$. In addition, biomass of Crucifer species was $84.84 \%$ higher than that of Asteraceae species. According to One-way ANOVAs, except for $C$. coronarium, fallen leaf aqueous extracts significantly affected biomass per plant of $B$. rapa and B. oleracea (both $P<0.05$, Table 2), and marginally affected biomass of L. sativa $(P=0.06$, Table 2$)$. With the concentration increased, aqueous extracts increased biomass of $B$. rapa by $65.22 \%$ to $108.70 \%$, while increased biomass of $L$. sativa by $86.51 \%$ to $124.71 \%$. Fallen leaf aqueous extracts did not significantly affect biomass of $B$. oleracea, if $40 \mathrm{~g} / \mathrm{L}$ extracts did not take into account, because that $40 \mathrm{~g} / \mathrm{L}$ extracts totally inhibited germination of B. oleracea (Fig. 7).

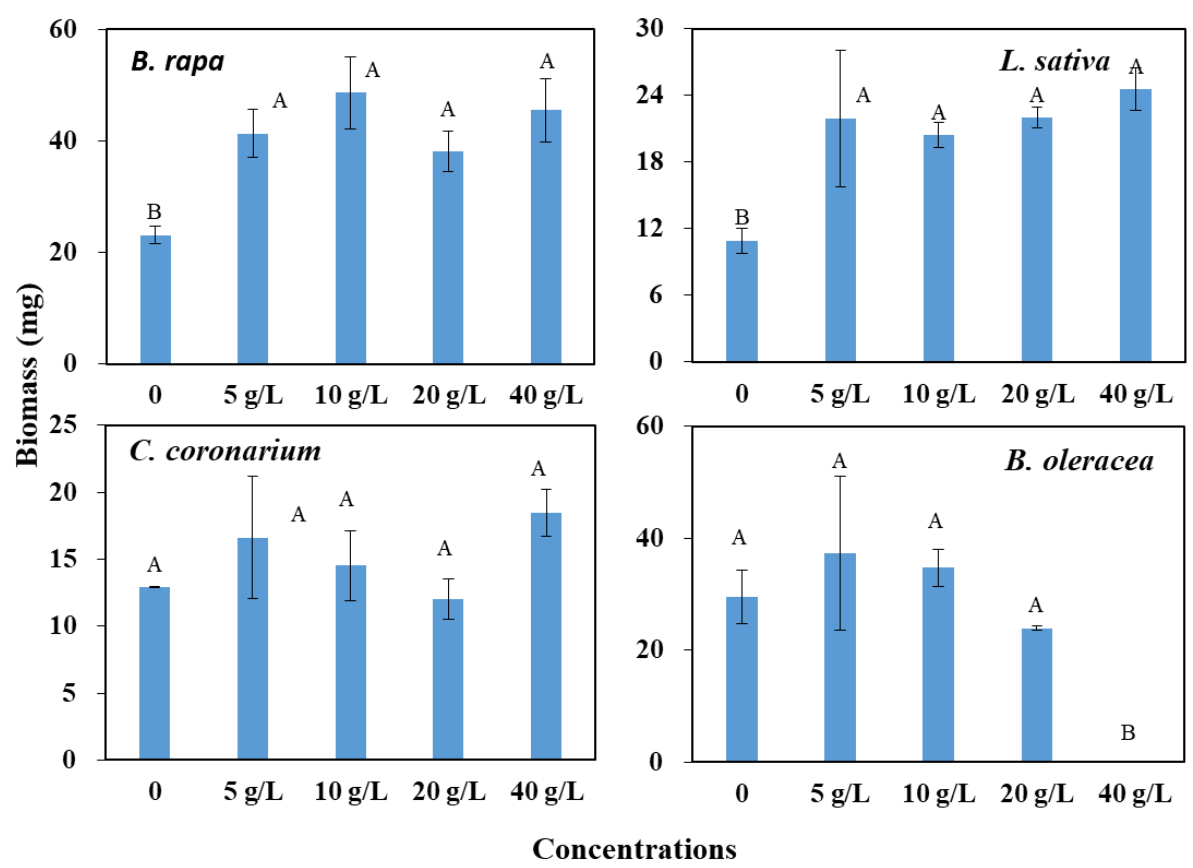

Figure 7. Effects of fallen leaf aqueous extracts of S. mukorossion on seedling biomass of the four vegetables (means $\pm 1 S E, n=3$ ). Means with the same uppercase letter are not significantly different $(P>0.05)$

The structural equation models (SEMs) showed that shoot length and root length can account for about $69.00 \%, 56.00 \%$, and $85.00 \%$ variation for B. rapa, L. sativa, and $B$. oleracea in biomass accumulation resulting from fallen leaf aqueous extracts, respectively (Fig. 8). It also showed that leaf aqueous extracts can account for about $25.00 \%$ variation in root length of $B$. rapa, which resulting in $69.00 \%$ variation in biomass accumulation in combination with shoot length (Fig. $8 a$ ). SEMs showed that leaf aqueous extracts can account for about $26.00 \%$ variation in shoot length of $L$. sativa, which resulting in $56.00 \%$ variation in biomass accumulation in combination with root length (Fig. 8b). Although SEM showed that leaf aqueous extracts could affect biomass of $B$. oleracea by affecting root growth, it may mainly result by totally inhibition of germination by $40 \mathrm{~g} / \mathrm{L}$ leaf aqueous extracts (Fig. 8d). 


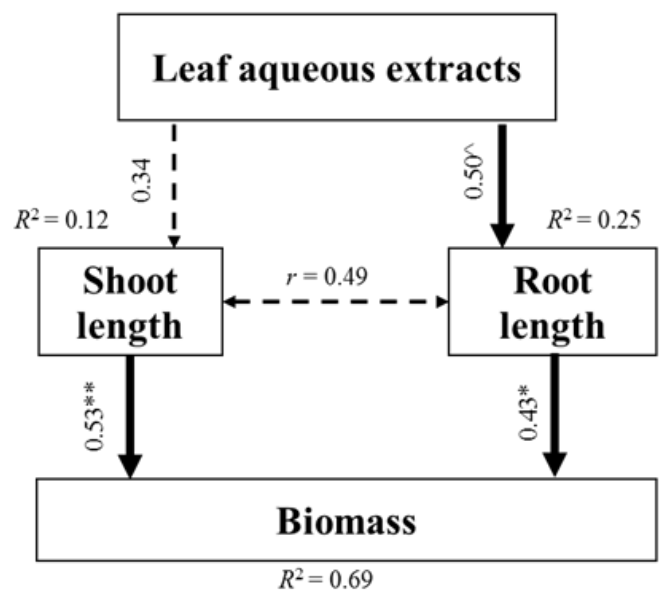

(a) B. rapa

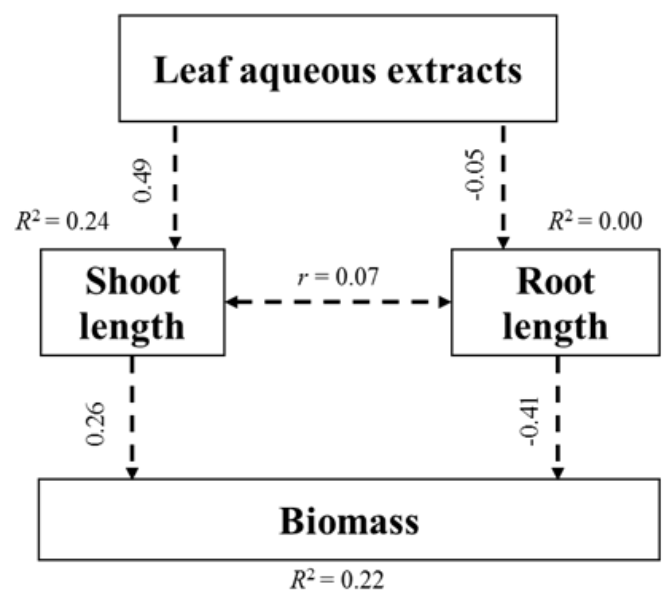

(c) C. coronarium

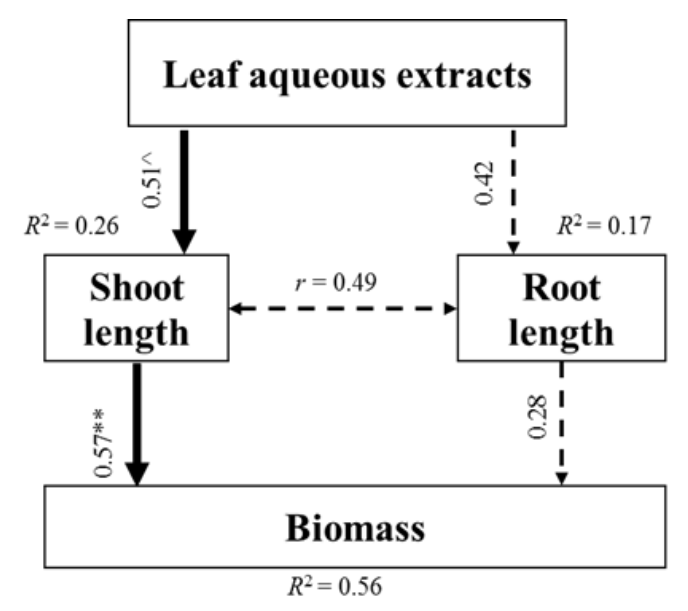

(b) L. sativa

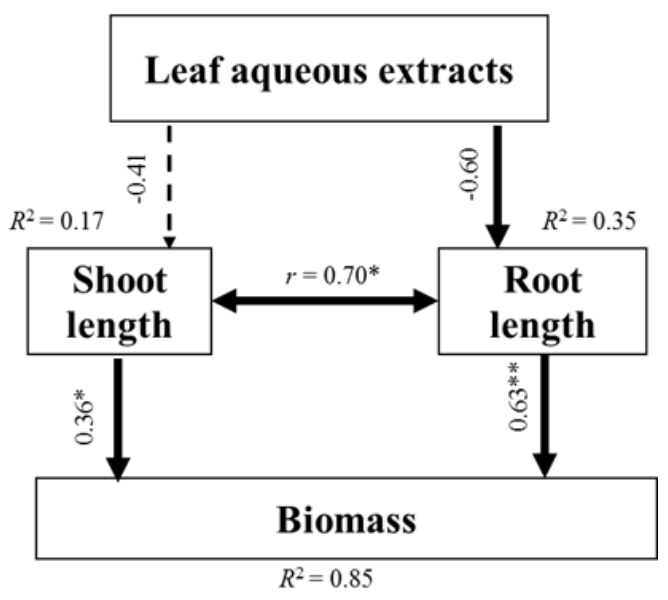

(d) B. oleracea

Figure 8. Structural equation models (SEMs) illustrating the direct and indirect effects of leaf aqueous extracts of $S$. mukorossi on seedling biomass. Boxes represent measured variables in the model. Values associated with single-headed arrows are the direct path coefficients. Values

associated with double-headed arrows indicate the correlation coefficients. Solid arrows indicate significant relationships and dashed arrows indicate insignificant relationships in the model. The $R^{2}$ values indicate the proportion of variance explained. ** indicates a significant difference at $P<0.001 ; *$ indicates a significant difference at $P<0.05 ; \wedge$ indicates a significant difference at $P<0.10$

\section{Discussion}

\section{Impacts on seed germination}

Our results demonstrated that fallen leaf aqueous extracts of high concentration of $S$. mukorossi significantly inhibited seed germination of all tested vegetables. Our results were accordance with previous studies demonstrated that plant extracts inhibit other plant seed germination (Ahn and Chung, 2000; Wang et al., 2009; Anwar et al., 2018; Ming et al., 2020), and the degree of inhibition increased with extract concentration increased (Chung and Miller, 1995; Ming et al., 2020). Aqueous extracts inhibited seed germination in three ways: decreased final germination percentage; decreased germination speed 
(prolonged germination time); and decreased germination synchronization, especially at higher concentration treatments. Allelochemicals in extracts may prevent growth of embryo, or caused the death (Cheng and Cheng, 2015). According to previous studies, leaf extracts of $S$. mukorossi contain different types of flavonoids such as quercetin, apigenin, kaempferol, and rutin (Singh and Kumari, 2015). Flavonoid is one of important allelopathic substances (Caser et al., 2020). Flavonoids excreted from roots or eluted from fallen leaves released into the surrounding soil are usually considered to inhibit germination (Mierziak et al., 2014). For example, flavones excreted from barley significantly inhibited seed germination of neighboring weeds (Kong et al., 2004a; Kong et al., 2007); flavones released by rice seedlings were enough in the defense of rice against weeds (Kong et al., 2004b). Flavones may be a key type of allecochemicals that could interfere potently with other organisms in ecosystems (Kong et al., 2007). Thus, we can speculate that allelochemicals such as flavonoids in fallen leaf aqueous extracts of $S$. mukorossi in our study may be harmful to seed embryo and can cause decreased of seed germination percentage, germination rate, and synchronization.

Allelopathy of aqueous extracts has been gaining more and more attention in weed management due to their disruption on establishment and growth of plants (Anwar et al., 2018; Carrubba et al., 2020; Caser et al., 2020). Allelopathy pressure is not always delivered by weeds to crops, but also could be delivered by crops to weeds (Van Volkenburg et al., 2020). For example, residues of rice could release allelochemicals to inhibit seed germination of neighboring weed (Rimando et al., 2001). Further studies conclusively showed that secondary metabolites, such as flavonoids, terpenoids, alkaloids, and cyanogenic glycosides, which usually involved in aqueous extracts, could play important roles in plants and other organism interactions (Kong et al., 2019). Therefore, allolochemicals of aqueous extracts has become a new branch of herbicide development (Macías et al., 2007; Kong et al., 2019), because these compounds can be directly used (Duke et al., 2000). As bioherbicides, aqueous extracts are biodegradable and environmental friendly because they are not halogenated and are generally safer for non-target organisms (Scognamiglio et al., 2012; Cheng and Cheng, 2015). Therefore, it is important to take advantage of the negative allelopathic effects on heterospecific plant in weed management for modern eco-agriculture (Macías et al., 2008).

\section{Impacts on seedling growth}

Our results demonstrated that fallen leaf aqueous extracts of $S$. mukorossi could stimulate seed vigor, and increased seedling length and biomass accumulation consequently, especially on appropriate concentration treatments. In natural ecosystem, nutrients released from plant litter especially fallen leaf through eluting are accessible for plants uptake in a more available forms (Adams and Angradi, 1996), as fallen leaf can account for more than $70 \%$ of aboveground litter (Robertson and Paul, 1999). Thus, nutrients that could stimulate seedling growth may release from leaves to aqueous extracts during soaking in our study. Seedlings grew in aqueous extracts as they grew in fertilized environments. They utilized nutrients from aqueous extracts to increased growth and accumulated more biomass. Our results were in accordance with that litter is an important process of nutrient cycling in ecosystems (Barbe et al., 2017), and play an important role in productivity (Adams and Angradi, 1996; Field et al., 2006; Barbe et al., 2017). It is meaningful that fallen leaf aqueous extracts could stimulate seedling growth of crop in agriculture. In order to meet the needs of population growth, we have to apply more chemical fertilizer into soil to maintain productivity in agriculture (Ashour et al., 2020). 
It makes soil degradation and environment pollution. Therefore, it is necessary to utilize all available sources of nutrients to maintain the productivity and fertility of soil (Cheng and Cheng, 2015). Aqueous extract of plant is one of the most important sources for supplying nutrients to crop and for improving soil health. More importantly, it is environment friendly. The applications of allelochmicals in crop production had been successful carried out (Iqbal et al., 2011). For example, the suitable application of allelochemicals could increase maize and canola yield (Cheema et al., 2013). Our results proved that aqueous extracts of plant could be applied in vegetable culture to stimulate yield.

Our results showed that the leaf aqueous extracts' effects were varied at different lifehistory stages for one species. According to our results, although leaf aqueous extracts of high concentrations inhibited seed germination of four vegetables, they did not decrease seedling growth of four vegetables. It meant that plants could need or tolerate different concentrations of nutrients at different life-history stage (Khan et al., 2009). Seed germination is rarely affected directly by nutrient in surrounding, because nutrients required for germination might mainly come from seed storage (Miransari and Smith, 2014; Peti et al., 2017). Furthermore, nutrient in extracts of high concentration in surrounding might play negative allelopathic effects or serve as an osmolyte to inhibit germination (Khan et al., 2009). Thus seeds germinated in leaf aqueous extracts exhibited germination inhibition in our study. However, after germination, seedling had to uptake nutrients from surrounding to stimulated growth, because storage in seed was not enough to provide nutrients for satisfying seedling growth requirements (Moles and Westoby, 2004). Therefore, the four vegetable seedlings could stimulate growth via absorbing nutrients from fallen leaf aqueous extracts in our study, as fallen leaf aqueous extracts may work as nutrients sources (Khan et al., 2009). It meant that we should apply aqueous extracts of different concentrations at different stages to stimulate plant growth.

\section{Impacts on different vegetables}

Our results showed that the responses to aqueous extracts could not only vary with phylogenetic characteristics, but also could vary with morphological characteristics of cultivated vegetables. Compared to Asteraceae species, Crucifer species exhibited better performances of seed germination and seedling growth according to two-way ANOVAs in our results. It proved that the effects of aqueous extracts were related to phylogenetic relationship. However, our results also demonstrated that the aqueous extracts influenced seedling biomass could through different pathways according to SEMs. For example, $B$. rapa and $B$. oleracea, two Crucifer species, exhibited different responses to aqueous extracts. Results from SEMs indicated that leaf aqueous extracts could account for shoot length and root length variance for $B$. rapa, resulting in biomass accumulation stimulation. Although shoot length and root length variance could significantly explain the biomass accumulation variance of $B$. oleracea, aqueous extracts could not stimulate biomass if the $40 \mathrm{~g} / \mathrm{L}$ concentration was not being taken into account because no seed germinated under $40 \mathrm{~g} / \mathrm{L}$ concentration. Similarly, L. sativa and C. coronarium, two Asteraceae species, also exhibited different responses to aqueous extracts. Aqueous extracts could account for root length variance for $L$. sativa, resulting in biomass accumulation stimulation. However, aqueous extracts could not affect biomass accumulation of $C$. coronarium. These results demonstrated that although Crucifer species exhibited better performances than Asteraceae species, morphological characteristic of each species maybe more important. It has been proved that domesticated 
plants such as cultivated vegetables may differ widely in appearance from their wild progenitors, most of which are associated with seed germination and seedling growth (Abbo et al., 2014). During domestication, cultivated vegetables are produced by different modifications of leaf, shoot or root system, biomass allocation, and relatively growth rate consequently (Shannon and Grieve, 1998). Therefore, cultivated vegetables could response to environment changes depend on morphological characteristics. In our study, $B$. rapa, and $L$. sativa are common leaf vegetables, $B$. olerace $a$ is one corm leaf vegetable, and the edible part of $C$. coronarium mainly is stem. The common leaf vegetable was selected for bigger leaf; the stem vegetable was selected for longer stem during cultivating. It was proved by our results which showed aqueous extracts significantly stimulated biomass, and/or shoot length of $B$. rapa, L. sativa, and $C$. coronarium. Whereas, the corm leaf vegetable, with shortened stem and form a compact, hard head, was not usually selected for longer aboveground component. Furthermore, empirical observations found that the common leaf vegetables used in our study took about 30-45 days from colonization to maturity, and B. oleracea took about 60 days. It meant that growth strategies of the common leaf or stem vegetable are taking advantage of environmental nutrients to stimulate aboveground component height and biomass as quickly as possible. However, as the corm leaf vegetable, B. oleracea had longer growth period to accumulate biomass (Paez-Garcia et al., 2015). Thus, we cannot investigate as significant difference as the other three vegetables exhibited on early growth stage for B. oleracea.

\section{Conclusions}

Our results demonstrated that fallen leaf aqueous extracts of $S$. mukorossi could inhibit germination and stimulate seedling growth and biomass accumulation of $B$. rapa, L. sativa, $C$. coronarium and $B$. oleracea, especially at appropriate concentration treatments. Furthermore, the effects of fallen leaf aqueous extracts on seedlings were not only related to phylogenetic relationship, but also related to morphological characteristics of cultivated vegetables. According to our study, we could take advantage of the negative allelopathic effects of fallen leaf aqueous extracts of $S$. mukorossi on germination in weed management, and the positive allelopathic effects on seedling growth and biomass accumulation to stimulate crop yield in agriculture. The occurrence of significant effects of fallen leaf aqueous extracts on seed germination and seedling growth represents a step forward in the study of weed management and organic fertilizer through allelochemicals. Further laboratory study and filed trial are both suggested in the future, involving to identify the active components of the fallen leaf aqueous extracts of $S$. mukorossi, and develop more comprehensive and evaluate the impacts on common weeds or crops.

Acknowledgements. This research was funded by Western Young Scholars Program of Chinese Academy of Science (XAB2019AW16), the Scientific Research Program of Shaanxi Province (2019JQ-436), and the Scientific Research Program of Xi'an City (2019112913CXSF007SF017). We thank Fangbing Ding, Shaoli Mao, Ying Zhang, Qian Wei, Guoqing Bai for their helps in collecting fallen leaves, making aqueous extracts, and providing vegetable seeds in the study. 


$$
-345 \text { - }
$$

\section{REFERENCES}

[1] Abbo, S., van-Oss, R. P., Gopher, A., Saranga, Y., Ofner, I., Peleg, Z. (2014): Plant domestication versus crop evolution: a conceptual framework for cereals and grain legumes. - Trends Plant Sci. 19: 351-360.

[2] Adams, M. B., Angradi, T. R. (1996): Decomposition and nutrient dynamics of hardwood leaf litter in the Fernow Whole-Watershed Acidification Experiment. - Forest Ecol. Manag. 83: 61-69.

[3] Ahn, J. K., Chung, I. M. (2000): Allelopathic potential of rice hulls on germination and seedling growth of barnyardgrass. - Agric. J. 92: 1162-1167.

[4] Anwar, T., Ilyas, N., Qureshi, R., Munazir, M., Anwar, P., Rahim, B. Z., Ansari, K. A., Panni, M. K. (2018): Allelopathic potential of lantana camara against selected weeds of wheat crop. - Appl. Ecol. Env. Res. 15: 5405-5421.

[5] Ashour, M., El-Shafei, A. A., Khairy, H. M., Abd-Elkader, D. Y., Mattar, M. A., Alataway, A., Hassan, S. M. (2020): Effect of Pterocladia capillacea seaweed extracts on growth parameters and biochemical constituents of Jew's Mallow. - Agronomy 10: 420.

[6] Barbe, L., Jung, V., Prinzing, A., Bittebiere, A. K., Butenschoen, O., Mony, C. (2017): Functionally dissimilar neighbors accelerate litter decomposition in two grass species. New Phytol. 214: 1092-1102.

[7] Callaway, R. M., Aschehoug, E. T. (2000): Invasive plants versus their new and old neighbors: a mechanism for exotic invasion. - Science 290: 521-523.

[8] Campos, J. A., Peco, J. D., García-Noguero, E. (2019): Antigerminative comparison between naturally occurring naphthoquinones and commercial pesticides. Soil dehydrogenase activity used as bioindicator to test soil toxicity. - Sci. Total Environ. 694: 133672.

[9] Carrubba, A., Labruzzo, A., Comparato, A., Muccilli, S., Spina, A. (2020): Use of plant water extracts for weed control in durum wheat (Triticum turgidum L. Subsp. durum Desf.). - Agronomy 10: 364.

[10] Caser, M., Demasi, S., Caldera, F., Dhakar, N. K., Trotta, F., Scariot, V. (2020): Activity of Ailanthus altissima (Mill.) swingle extract as a potential bioherbicide for sustainable weed management in Horticulture. - Agronomy 10: 965.

[11] Cheema, Z., Farooq, M., Khaliq, A. (2013): Application of allelopathy in crop production: success story from Pakistan. - In: Cheema, Z. A., Farooq, M., Wahid, A. (eds.) Allelopathy. Springer-Verlag Press, Berlin Heidelberg.

[12] Cheng, F., Cheng, Z. (2015): Research progress on the use of plant allelopathy in agriculture and the physiological and ecological mechanisms of allelopathy. - Front. Plant Sci. 6: 1020.

[13] Chou, C. H. (1999): Roles of allelopathy in plant biodiversity and sustainable agriculture. - Crit. Rev. Plant Sci 18: 609-636.

[14] Chung, I. M., Miller, D. A. (1995): Natural herbicide potential of alfalfa residues on selected weed species. - Agron. J. 87: 920-925.

[15] Diao, S. F., Jiang, J. M., Yi, H., Yue, H. F., Dong, R. X., Sun, H. G., Shao, W. H. (2016): Flowering phenology of the multipurpose tree species Sapindus mukorossi Gaertn. in low mountain areas of Zhejiang Province. - Acta Ecologica Sinica 36: 6226-6234.

[16] Duke, S. O., Dayan, F. E., Romagni, J. G., Rimando, A. M. (2000): Natural products as sources of herbicides: current status and future trends. - Weed Res. 40: 99-111.

[17] Fernandez, C., Monnier, Y., Ormeño, E., Baldy, V., Greff, S., Pasqualini, V., Mévy, J. P., Bousquet- Mélou, A. (2009): Variations in allelochemical composition of leachates of different organs and maturity stages of Pinus halepensis. - J. Chem. Ecol. 35: 970-979.

[18] Field, B., Jordan, F., Osbourn, A. (2006): First encounters-deployment of defence-related natural products by plants. - New Phytol. 172: 193-207.

[19] Hierro, J. L., Callaway, R. M. (2003): Allelopathy and exotic plant invasion. - Plant Soil 256: 29-39. 
[20] Iqbal, M. F., Kahloon, M. H., Nawaz, M. R., Javaid, M. I. (2011): Effectiveness of some botanical extracts on wheat aphids. - J. Anim. Plant Sci. 21: 114-115.

[21] Khan, W., Rayirath, U. P., Subramanian, S., Jithesh, M. N., Rayorath, P., Hodges, D. M., Critchley, A. T., Craigie, J. S., Norrie, J. (2009): Seaweed extracts as biostimulants of plant growth and development. - J. Plant Growth Regul. 28: 386-399.

[22] Kong, C. H., Xu, X. H., Zhou, B., Hu, F., Zhang, C. X., Zhang, M. X. (2004a): Two compounds from allelopathic rice accession and their inhibitory activity on weeds and fungal pathogens. - Phytochemistry 65: 1123-1128.

[23] Kong, C. H., Laing, W. J., Xu, X. H., Hu, F., Wang, P., Jiang, Y. (2004b): Release and activity of allelochemicals from allelopathic rice seedlings. - J. Agric. Food Chem. 52: 2861-2865.

[24] Kong, C. H., Zhao, H., Xu, X. H., Wang, P., Gu, Y. (2007): Activity and allelopathy of soil of flavone O-Glycosides from rice. - J. Agric. Food Chem. 55: 6007-6012.

[25] Kong, C. H., Xuan, T. D., Khanh, T. D., Tran, H. D., Trung, N. T. (2019): Allelochemicals and signaling chemicals in plants. - Molecules 24: 2737.

[26] Ling, Y., Zhang, Q., Zhong, W., Chen, M., Gong, H., He, S., Liang, R., Lv, J., Song, L. (2019): Rapid identification and analysis of the major chemical constituents from the fruits of Sapindus mukorossi by HPLC-ESI-QTOF-MS/MS. - Nat. Prod. Res. 34: 2144-2150.

[27] Macías, F. A., Molinillo, J. M. G., Varela, R. M., Galindo, J. C. G. (2007): Allelopathy-a natural alternative for weed control. - Pest Manag. Sci. 63: 327-348.

[28] Macías, F. A., Oliveros-Bastida, A., Marin, D., Carrera, C., Chinchilla, N., Molinillo, J. M. G. (2008): Plant biocomunicators: their phytotoxicity, degradation studies and potential use as herbicide models. - Phytochem. Rev. 7: 179-194.

[29] Mallik, A. U., Pellissier, F. (2000): Effects of Vaccinium myrtillus on Spruce regeneration: testing the notion of coevolutionary significance of allelopathy. - J. Chem. Ecol. 26: 21972209.

[30] Mallik, A. U. (2003): Conifer regeneration problems in boreal and temperate forests with ericaceous understory: role of disturbance, seedbed limitation, and keystone species change. - Crit. Rev. Plant Sci. 22: 341-366.

[31] Mierziak, J., Kostyn, K., Kulma, A. (2014): Flavonoids as important molecules of plant interactions with the environment. - Molecules 19: 16240-16265.

[32] Ming, Y., Hu, G. X., Li, J., Zhu, Z. J., Fan, X. M., Yuan, D. Y. (2020): Allelopathic effects of Castanea henryi aqueous extracts on the growth and physiology of Brassica pekinensis and Zea mays. - Chem. Biodivers: e2000135.

[33] Miransari, M., Smith, D. L. (2014): Plant hormones and seed germination. - Environmen. Exp. Bot. 99: 110-121.

[34] Moles, A. T., Westoby, M. (2004): Seedling survival and seed size: a synthesis of the literature. - J. Ecol. 92: 372-383.

[35] Morgan, E. C., Overholt, W. A. (2005): Potential allelopathic effects of Brazilian pepper (Schinus terebinthifolius Raddi, Anacardiaceae) aqueous extract on germination and growth of selected Florida native plants. - J. Torrey Bot. Soc. 132: 11-15.

[36] Ojija, F., Arnold, S. E., Treydte, A. C. (2019): Bio-herbicide potential of naturalised Desmodium uncinatum crude leaf extract against the invasive plant species Parthenium hysterophorus. - Biol. Invasions 21: 3641-3653.

[37] Ooka, J. K., Owens, D. K. (2018): Allelopathy in tropical and subtropical species. Phytochem Rev. 17: 1225-1237.

[38] Paez-Garcia, A., Motes, C. M., Scheible, W., Chen, R., Blancaflor, E. B., Monteros, M. J. (2015): Root Traits and phenotyping strategies for plant improvement. - Plants 4: 334-355.

[39] Peti, E., Schellenberger, J., Németh, G., Málnási Csizmadia, G., Oláh, I., Török, K., Czóbel, S. Z., Baktay, B. (2017): Presentation of the HUSEED ${ }^{\text {wild }}$ - a seed weight and germination database of the Pannonian flora - through analysing life forms and social behaviour types. - Appl. Ecol. Env. Res. 15: 225-244. 


$$
-347 \text { - }
$$

[40] Ranal, M. A., Santana, D. G. D. (2006): How and why to measure the germination process? - Braz. J. Bot 29: 1-11.

[41] Rice, E. L. (1984): Allelopathy, 2nd edition. - Academic Press: New York.

[42] Rimando, A. M., Olofsdotter, M., Dayan, F. E., Duke, S. O. (2001): Searching for rice allelochemicals. - Agronomy J. 93: 16-20.

[43] Robertson, G. P., Paul, E. A. (1999): Decomposition and soil organic matter dynamics. In: Sala, O. E., Jackson, R. B., Mooney, H. A., Howarth, R. W. (eds.) Methods of ecosystem science. Springer Press, New York.

[44] Rout, M. E., Callaway, R. M. (2009): An invasive plant paradox. - Science 324: 724-725.

[45] Scognamiglio, M., Esposito, A., D’Abrosca, B., Pacifico, S., Fiumano, V., Tsafantakis, N., Monaco, P., Fiorentino, A. (2012): Isolation, distribution and allelopathic effect of caffeic acid derivatives from Bellis perennis L. - Biochem. Syst. Ecol. 43: 108-113.

[46] Shannon, M. C., Grieve, C. M. (1998): Tolerance of vegetable crops to salinity. - Sci. Hortic-Amsterdam 78: 5-38.

[47] Singh, R., Kumari, N. (2015): Comparative determination of phytochemicals and antioxidant activity from leaf and fruit of Sapindus mukorrossi Gaertn. - a valuable medicinal tree. - Ind. Crop. Prod. 73: 1-8.

[48] Turk, M. A., Tawaha, A. M. (2003): Allelopathic effect of black mustard (Brassica nigra L.) on germination and growth of wild oat (Avena fatua L.). - Crop Prot. 22: 673-677.

[49] Van Volkenburg, H., Guinel, F. C., Vasseur, L. (2020): Impacts of smooth pigweed (Amaranthus hybridus) on cover crops in Southern Ontario. - Agronomy 10: 529.

[50] Veen, G. F., Fry, E. L., ten Hooven, F. C., Kardol, P., Morriën, E., De Long, J. R. (2019): The role of plant litter in driving plant-soil feedbacks. - Front. Environ. Sci. 7: 168.

[51] Wang, X. F., Xing, W., Wu, S. H. (2009): Allelopathic effects of seed extracts of four wetland species on seed germination and seedling growth of Brassica rapa spp.pekinensis, Oryza rufipogon and Monochoria korsakowii. - Fresen. Environ. Bull. 18: 1832-1838.

[52] Zheng, Y. L., Feng, Y. L., Zhang, L. K., Callaway, R. M., Valiente-Banuet, A., Luo, D. Q., Liao, Z. Y., Lei, Y. B., Barclay, G. F., Silva-Pereyra, C. (2014): Integrating novel chemical weapons and evolutionarily increased competitive ability in success of a tropical invader. - New Phytol. 205: 1350-1359. 